Running Head: RISK, NOSTALGIA, AND CHILDREN'S OUTDOOR PLAY

Risk, nostalgia, and the production of the ideal childhood in online commentary on children's outdoor play

\author{
Erin K. Sharpe \\ Brock University \\ Fenton Litwiller \\ University of Manitoba \\ Karen Gallant \\ Dalhousie University
}




\begin{abstract}
We use Foucauldian discourse analysis to examine comments posted online in response to news articles that reported on one Canadian neighbourhood's 'ban' on children's outdoor play. Our analysis showed that reader comments, both for and against the ban on street play, accessed discourses of risk that produced an idealized childhood based on close parental supervision. Additionally, nostalgic discourse, the feeling that unfettered, wholesome outdoor play has been lost and cannot be reclaimed, also made claims about who the ideal childhood is for. While marginalized children continue to experience disadvantage that inherently exposes them to risks daily, White, middle class children already have access to safer streets, both parent presence or unquestioned but appropriate parental absence, and play in the streets can be part of their everyday lives. We consider how the idealized childhoods produced by discourses of risk and nostalgia influence the materiality of children's outdoor play, including how children's time is organized and who gets to organize it, how play is experienced and who gets to experience it; in ideal ways, in ideal spaces, and for the ideal child.
\end{abstract}

Keywords: Childhood, outdoor play, risk, nostalgia, online commentary 


\section{Risk, nostalgia, and the production of the ideal childhood in online commentary on children's outdoor play}

\section{Introduction}

In everyday rhetoric, children's outdoor play is constructed as both dangerous and essential. Because of the documented benefits of outdoor play for children's healthy development, the medical establishment (e.g., American Academy of Pediatrics) encouraged doctors to 'prescribe play' (Yogman et al., 2018), and professional coalitions from multiple countries have released position papers promoting independent children's outdoor play (e.g., Tremblay et al. (2015) in Canada; Outdoor Play and Learning Coalition Position Statement (2018) in Scotland). At the same time, fears of danger in many forms (stranger danger, injury) have precipitated a decline in opportunities for children to play outside, decreased children's 'roaming range' (Derbyshire, 2007), and increased regulations and rules about, for example, what counts as a safe playground. Concerns about the risks of outdoor play have not only provoked significant anxiety but also corresponding nostalgia for simpler times, when children used to roam, alone and with friends, in natural landscapes. The confluence of these discourses introduces an impossible dilemma for parents and educators in providing children's play that is perceived as normal and acceptable (Alexander, Frohlich, \& Fusco, 2018).

In Canada, the topic of children's outdoor play drew nation-wide attention in the summer of 2018, when a strata neighbourhood (with lots owned individually and commons spaces communally owned) on Vancouver Island passed a bylaw prohibiting outdoor play in the common areas of the development. The new bylaw, which stated that the neighbourhood's streets and roads "may not be used for play, including hockey, baseball, basketball, 
skateboarding, chalk artistry, bicycling or other sports and recreational activities" (O'Connor, $2018,14)$ was first reported in a regional paper, then picked up by national news outlets including the National Post, $\mathrm{CBC}$, and Global News. Published in the National Post under the headline "No hockey, no bikes, no chalk drawings, you name it: This B.C. neighbourhood has declared a war on fun" and in CBC news as "No bike riding, no chalk drawings: Vancouver Island strata bans outside play on quiet road", these stories presented the events related to the ban and neighbourhood residents' perspectives. Online, these news stories generated intensive engagement from readers, with 95 comments on the National Post story and over 180 on the CBC story.

Risk and nostalgia in the context of children's play have been noted in previous scholarship, recently by Alexander, Frohlich, and Fusco (2019), and earlier by Jackson and Scott (1999, p. 87), who characterized the climate of children's play as one of "heightened risk awareness coupled with a nostalgia for an imagined past in which children played safely throughout a carefree innocent childhood" (Jackson \& Scott, 1999, p. 87). This research builds on previous scholarship by examining how discourses of risk and nostalgia operate in online commentary responses to news stories about children's play. Online commentary offers an opportunity to examine how the multiple and competing practices and beliefs about children's outdoor play are produced; that is, the mechanism through which these realities came to be. In this paper, we examine the online reader commentary about the neighbourhood 'ban on fun' using Foucauldian discourse analysis (FDA), and show how discourses of risk and nostalgia discursively produce an ideal, but inaccessible, childhood. These ideas about childhood 
influence the materiality of children's outdoor play including how time is organized and who gets to organize it, and how play is experienced and who gets to experience it.

\section{Literature Review}

\section{Risk and Childhood}

Research has identified that children growing up in the 2000s and later have greater restrictions placed on their everyday movements compared to the experiences of children of previous generations; which keeps them closer to home, and often in the home (Gaster, 1991;

O'Brien, Jones, Sloan, \& Rustin, 2000; Rixon, Lomax, \& O'Dell, 2019). Over the past 20 years, the topic of children's 'disappearing' outdoor play has become omnipresent; discussed frequently in academic literature, mainstream press, and national newspapers (Alexander et al., 2018). Research and public opinion suggest that the decline in children's outdoor play is also a result of a heightened concern and aversion of 'risks' among parents and children ( $O$ 'Brien et al., 2000; Pain, 2006; Valentine, 2017; Vandermaas-Peeler, Dean, Biehl, \& Mellman, 2019). Studies have documented how concerns about 'stranger danger' instilled fear in parents who consequently restricted their children's play in public space (Allin, West, \& Curry, 2014; Valentine, 2017), and identified concern among parents (mothers) of the risk of injury to children caused by automobiles as they negotiate busy roads and parking lots (McLaren \& Parusel, 2015; Smyth \& Craig, 2017) and playgrounds with climbing structures (Alexander et al., 2018).

The proliferation of risk discourses about outdoor play and many other social practices is characteristic of the 'risk society' - a society in which the assessment and management of risk is no longer only in the realm of science and technology, but becomes an everyday concern of 
people (Beck, 1992). Risk society also influences the child's relationship to the parent and the parental role in managing a child's play time and space. Hoffman (2010) argued that the conditions of risk society encourages parents to engage in rigorous risk management, that parenting in "a climate of 'inflated risk' leads parents to micromanage all aspects of their children's lives in an effort to protect the child from adverse experiences" (p. 387). For example, in order to guard children against the dangers of the street, parents increasingly escort children to and from educational and leisure-time activities (Fotel, 2007; O'Brien et al., 2000). Not surprisingly, this type of laborious and emotionally present 'intensive parenting' is gendered (Hays, 1996), with mothers actively managing stranger danger, rough play from other children, and preventing the 'poor' decisions of their children through hyper-surveillance; also known as helicopter parenting. Failure to manage risk "labels individuals [i.e.., children] as 'risky', generating both societal disapproval and also potentially feelings of personal shame [for parents]" (Lester \& Russell, 2014, p. 243).

Children's play has also been influenced by neoliberal ideologies that work to reconfigure childhood from a time a time of freedom and exploration to a time to "invest in the future" (Smeyers, 2010, p. 271). Fears of economic insecurity and downward mobility - for themselves and for their children - have encouraged among parents a more highly involved and intensified style of parenting, underpinned by a logic that by spending as much time with their children as possible, parents are able to 'immunize' their children against future problems (Widding, 2015). Children's free time has become increasingly organized with 'productive' extracurricular and enrichment activities - thereby both 'instrumentalizing' (i.e., being purpose driven) (Alexander et al., 2018) and 'institutionalizing' childhood (Holloway \& Pimlott-Wilson, 
2014; Smyth \& Craig, 2017). For parents, neoliberal influences have also intensified the parenting role, requiring of them much more presence (Elvin-Nowak, 1999). Thus, childhood is lived under closer adult supervision and within spaces specifically designated for play.

A number of movements concerned with children's declining outdoor play have also influenced the multiplicity of discourses around children's play. For example, the 'free-range kids' movement, spearheaded by Skenazy (2010), promotes children's independent mobility - the ability to move around in public spaces without adult accompaniment. Similarly, the friluftsliv movement in Scandanavia (Sandester, 2014) and the 'nature-deficit disorder' (Louv, 2005) and adventure playground movements in Canada and the U.S. (Osler, 2016) highlight the importance of children engaging in natural areas and playgrounds and taking more child-assessed 'calculated risks'. These varied movements have primarily been framed within human rights frameworks, in which outdoor play is positioned as a right of children (United Nations Children's Fund, 1989), and benefits frameworks, which highlight the many ways that outdoor play is beneficial to children and society. For example, Canada's position statement frames children's outdoor play as an antidote to childhood obesity caused by physical inactivity and excessive screen time (Tremblay et al., 2015). In a recent study that compared US and Danish parents in terms of their values and practices related to outdoor play in nature settings, parents of both nationalities valued children's play in natural environments as a means of cultivating an appreciation of nature, and benefits to physical health and cognitive functioning. However, US parents perceived many barriers to such play, related to safety, ease of parental surveillance, and weather (Vandermaas-Peeler et al., 2019). Thus, while North American parents appreciate the value of outdoor play, their concerns related to risk impair their ability to act on these values. With the introduction of these counter movements and the increased valuing of outdoor play, 
scholars have shown that, in addition to experiencing shame for not protecting their children, mothers were also judged by their peers if they did not allow their children enough freedom in the outdoors to experience the benefits articulated above (Allin et al.,, 2014). Some parents were therefore positioned as less than capable if they failed to actively 'develop' resilience in their children with enough exposure to risk cultivated through an open-air autonomy (Hoffman, 2010).

Alexander et al. (2018) pointed out how these multiple discourses circulating around children's outdoor play dovetail with discourses of criminalization (e.g., the illicit behavior that results when parents allow too much childhood freedom) and responsibilization (e.g., the loss of potential learning, independence, and future success of children whose parents do not allow enough freedom to play). For parents and educators then, it becomes risky to allow play but also risky to not allow play. Thus parents, particularly mothers, are caught in a double bind between avoiding behavior that would be considered 'helicopter parenting' while also being intensively present.

\section{Nostalgia and Childhood}

Increased surveillance of and restrictions on children's outdoor play is accompanied by a sense of loss when comparing childhood freedoms today with the freedom afforded to past generations. Kehily $(2010$, p. 172) noted that the notion of childhood in 'crisis' is often invoked in media commentary and public discourse, and the prevailing assumption that childhood is "not what it used to be". Nostalgic discourses of childhood encourage romanticized notions of a childhood past singularly depicted as an idyllic period that afforded children free time and plentiful natural settings that innately fostered freedom and exploration, adventure, fresh air, independence, physical activity and wholesome fun (Karsten, 2005). Through the repetitive telling of these storied memories, and contrasting the present with idealized versions of the simpler, more meaningful, and more wholesome 
past, nostalgic discourses of childhood produce a sense of disappointment, yearning, and anxiety in the present (Barnes, Waitt, Gill, \& Gibson, 2006; Watson \& Wells, 2005; Kenny, 2007).

However, Karsten's (2005) study of current and past generations of children's memories of play revealed that children themselves did not always prefer the outdoor play of this nostalgic past. Rather, it was sometimes the result of necessity for large families living in small homes where indoor space was "adult space" (p. 275), and children had associated responsibilities such as caring for younger siblings. Further, such nostalgic recollections of childhood often fail to account for inequities in access to or allocation of the very resources and experiences about which we feel nostalgic (Barnes et al., 2006; Watson \& Wells, 2005); in this case, children's opportunities for unfettered independence and outdoor play in a relatively safe but adventure-ful neighbourhood. Watson and Wells (2005) questioned to what extent nostalgia masks historical inequities of geographical social divisions, racism, and sexism. They wrote: “...nostalgia can perform the function of whitewashing the past and producing a collective memory that reflects only some peoples' lives" (p. 20).

It is important, then, to consider whose childhood is idealized in discourses that lament the loss of children's outdoor play. For example, Giles, Bauer, and Darroch (2019) questioned whether the recent impetus for children to engage in more and 'riskier' outdoor play, as encouraged in the various movements highlighted above, is beneficial for all children. They argued that calling for children to engage in greater risky play may be detrimental to children who are already at higher risk of injury. In the Canadian context this is children who live in rural or northern areas, have Indigenous identities, or whose families live on low incomes. By drawing attention to the differential rates of injury among children, Giles et al. expose how the risky play movement is a movement of the White urban bourgeois 
- people who have the freedom to choose to take risks, because their lives are already fairly safe, and they face little real danger when they move further, and more visibly, into the public sphere.

\section{Methods}

In this paper we trace discourses of risk and nostalgia about children's outdoor play as invoked in reader comments about a neighbourhood 'ban on play' published by online news outlets. The story was first published in a local news outlet, the Chemainus Valley Courier, on June 29, 2018. Over July 4 to 11 , the story was published in 13 news outlets ( 6 newspapers, 7 news networks). All of these news outlets offered readers the option to comment on the story, and in total over 1100 comments were posted across these 13 outlets. In this analysis, we examined the online comments posted in response to articles published by the CBC (181 comments) and National Post (95 comments). We selected these outlets because we expected that the comments would consider the topic of children's outdoor play more abstractly, as compared to more local sites where the commentary would be more focused on the specific case. Focusing on two news outlets in full allowed us to follow the 'conversations' of the commenters, which was useful for identifying points of contention and significant discursive elements.

\section{Online comments as data sources}

Jackson and Valentine (2014) wrote that comments sections associated with online news media can “...create an interconnected discussion that focuses not only on a political or social position but also brings emotions into political discussions and enables an engagement with the everyday, micro scale through which people live their daily lives'” (p. 201). Critiques of online settings as forums for public discourse focus on the potential for inflammatory, extreme, and/or abusive (i.e., sexist, racist) comments, particularly since the lack of social and spatial proximity to other participants can erode commenters' sense of social responsibility (Hughey \& Daniels, 2013; Jackson \& Valentine, 2014). 
Further, concerns have been raised about inequities in access to online settings. The anonymous nature of online forums due to the lack of analytical data collected when individuals sign up for an account or displayed alongside their posts is associated both with an increased sense of safety in posting one's views, but also increased prevalence of aggressive comments and extreme views, and the extent to which discussion in online forums stray from the ideals of democratic discussion.

Despite these critiques of online forums, the anonymity of online settings means that commenters may be more comfortable, as compared with in-person settings, in sharing personal views. Even when the topics are not particularly personal or private, online forums serve as sites where individuals engage in discussion that reflects their personal ideals, and are considered to reflect more everyday and immediate responses to issues from "ordinary people" (Hanna, Scarles, Cohen, \& Adams, 2016, p. 1628), as compared with the more scripted opinions published online in wikis and blogs. Finally, as McDermott (2018) stated: “little research has been directed at considering either readers' comments specifically in relation to the news issue being covered, or exploring the discourses being reproduced and/or challenged in relation to the media's framing of said issues" (p. 176).

\section{Foucauldian discourse analysis}

A Foucauldian discourse analysis frames power as manifesting through everyday social interactions, rather than as inherently manifest in institutions, law, and held by an influential few. Discourse is a shared understanding that the language we use to communicate to one another represents ways of thinking and knowing about and ordering realities (Cheek, 2008); in other words, implicit realities are continually made evident, visceral, and material through the words we use to describe them. Foucault positioned discourse as "practices that systematically form the objects of which they speak" $(1972$, p. 49) and asserted that discourse is more than 
just language; he writes "it is this 'more' that we must reveal and describe" (Foucault, 1972, p.

49). Discourse is always active and productive, rather than necessarily restrictive or enabling, and accounts for current circumstances and materiality. Discourse facilitates, and makes real, bodies in compulsory ways by simultaneously disciplining particular bodies and regulating whole populations through normalizing broad surveillances, orderings of space, and personal scrutiny as techniques of control and discursive power (Foucault, 1990). To use Foucauldian discourse analysis (FDA) is to collectively analyze how statements, that which is articulated through minute instances of irony (Graham, 2005) and laughter (Szto, 2016), or a broad corpus of utterances, have productive effects including maintaining the status quo. In this way scholars using FDA ask how texts represent ways of knowing, and how these ways of knowing shape our understanding and practice of, say, children's play. Cheek wrote:

Foucauldian discourse analysis offers the potential to challenge ways of thinking about aspects of reality that have come to be viewed as being natural or normal and therefore tend to be taken for granted. It can enable us to explore how things have come to be the way they are, how it is that they remain that way, and how else they might have been or could be (p. 2).

Markula and Silk (2011) asserted that through FDA, texts can be analysed to show how power and discourse are interconnected, came to be, and produce subjectivity. They detail six steps to FDA, which we used to guide our collaborative approach to analysis. Markula and Silk note that first, the analysts decide on the objects or question to explore (how do we know about children's play?), and then the texts in which these objects are revealed through talk are identified. The third step focuses on the ways in which children's play is talked about (in this case, through risk and nostalgia). Then, the analysts determine statements, or how a number of 
concepts work together to articulate a common sense. Finally, analysts show the relationship of these statements to the larger framework of discourse and articulate how power is operating.

Our analysis was undertaken collaboratively. First, we the online commentary texts into a data analysis software (nVivo), and each researcher read and annotated the texts. Following this, a number of objects (e.g., 'outdoor play', 'the ban', 'acceptable play places,' 'parenting') were initially and collectively established. The researchers then iteratively engaged with the text, objects, and utterances to understand how statements of the common-sense beliefs articulated in the texts were collectively constructed (e.g., that the parent must oversee the child, but, not too much, and manage all risk) and held together with particular objects (i.e, the ideal childhood, risky play). We then considered the discursive framework of childhood (through invoking nostalgia, the ideal child and childhood and risky play is made coherent) and articulated how power is operating (e.g., nostalgia positions the speaker as expert and the White experience as ideal). As a research team, we brought our distinct theoretical positionalities and influences into the research process (e.g., queer, feminist, communitarian) and worked to hold open space for these different theoretical lenses to inform the analysis.

\section{Analysis}

\section{Discourses of risk and the idealized imaginary of children's outdoor play}

Not surprisingly, the news story about the ban on outdoor play generated commentary about what constituted appropriate children's play activities, play spaces, and adult oversight. For example, in debating whether the street was an appropriate play space for children, readers invoked multiple and conflicting discourses of risk. In the following comments, readers emphasized the potential of what might happen were the ban not in place. One reader alludes 
to bodily injury: "And when one of them got run over? Then what?" [National Post] and another to property damage: "I know the vehicles are getting damaged and there is a good chance someone's bike (or kid) is going to get backed over" [National Post]. Thus, the potential of injury or damage should be avoided because it could be avoided, since neighbourhoods are imagined as having other, safer places for children to play, such as playgrounds. Further, because ideal neighbourhoods have playgrounds, playing in the street is constructed as an unnecessary risk, a place that kids shouldn't play: “Children shouldn't be playing on roads. They should be playing in parks with supervision" [National Post].

At the same time online commenters also drew on discourses of risk to argue for the use of streets as settings for outdoor play. Similar to the arguments presented in the position papers of national coalitions, commenters framed outdoor play as the active, healthy and playful choice for children, and contrasted it to sedentary forms of indoor play, particularly play that involves screen time, like television watching or video game playing. As one commenter stated, "in an age where we are trying to encourage kids to be outside instead of in front of a TV or game console this [ban] is absolutely ludicrous" [CBC]. Although the position of this reader is encouraging of outdoor play, the comments also demonstrate how discourses of risk undergird benefits-based framings of children's play. For example, one commenter emphasized the societal risks produced by a ban on play: a lack of stimulation impacting the child's ability to be functioning, contributing adults:

This is absolutely ridiculous...so many people complaining about "kids these days" and wondering why kids are so lazy but then policy like this comes into play which basically bans childhood!...Schools are already banning kids from running on pavement, doing cart wheels, and playing tag while at recess so now not only are kids not allowed to be kids at school but also aren't allowed to be kids at home? I am not sure what the 
solution to all of this is but this lack of stimulation for the child growing up will really impact their livelihood in the future. [National Post]

Smeyers (2010) explained that "the language of risk is actually a language of what is at risk in the future" (p. 283). In other words, risk operates through the language of "what if", or potentialities. On one hand, comments promote outdoor play by reminding readers of the larger problems or "what if" potentialities if children are not given the opportunity to be active outdoors: "If you're against finding a way to let children be active in our neighbourhoods then your [sic] part of the problem, not the solution" [CBC]. However, they also (re)produce notions of children as always-at-risk, and in need constant vigilance. Thus, the childhood that is idealized is one in which children playing outside are protected against danger, in part through the containment of outdoor play in (assumedly) safe places that are a priori designated for play. It also produces a childhood in which the close and constant supervision of children is normalized and expected. Indeed, readers invoked risk discourses in their comments directed toward parents, whom they reprimand for allowing their children to play in the street. To these commenters, parents were either lazy: "Take them to the gosh darn park. Take them to the beach. Get parenting, stop being lazy and just letting them play in the street" [National Post], irresponsible: "Parents who let their kids play near cars are being irresponsible and lazy. Go to the playground people!" [National Post], or too focused on themselves:

Why let your kids play on the street, it just is not safe for them. We have parks, school grounds, and play grounds for playing but apparently too many parents are too lazy or too busy (self-imposed) to spend time with their kids and take to safe areas. [National Post]

In managing conflicting discourses of risk related to street play, the task assigned to parents is risk management: finding a way to minimize the dangers of outdoor play while also achieving 
its benefits to provide children with the best possible start to a successful life (Alexander et al., 2018). The focus on risk management in the discursive framework of children's outdoor play constructs a subjectivity of the 'good parent' as a skillful risk manager who stays close to the child. Allin, Curry, and West (2014, p. 655), wrote that "parents, particularly mothers, make decisions [for their children] around risk within the context of discourses around 'good mothering' as well as the contradicting public and societal discourses associated with risk and engaging in outdoor play". However, because risks operate in the realm of potentialities - of "what ifs" - risk management requires parents to be in a state of constant vigilance, engaged in a never-ending process of risk assessment because "risks exist everywhere":

Getting out of bed is a risk and it is a parent's responsibility to teach their children to effectively manage risks that exist everywhere. I am all for rules when it is about protecting others --- e.g., drinking and driving --- but enough already with the rules [about children not playing in the street] based on [the strata knowing] better than you what is good for you. [National Post]

As evident in the quote above it is the parent, and not the surrounding community, upon which risk management falls. Proper vigilance and supervision is one way that people including parents themselves - differentiated between good and bad parents. As in Widding (2015), parents defined other bad parents as those who were "unwilling to take on the [supervisory] responsibilities...immature and incapable of acting responsibly and is, therefore, him- or herself something of a child" (p. 56). Smith and Craig (2017) identified very little active resistance among parents to intensive parenting standards, although parents felt conflicted about their "obligation to be vigilant" (p. 120).

Indeed, commenters celebrated the strategies they used (or saw parents use) in the ongoing task of risk management of children's outdoor play. One reader described the parents 
and children in their neighbourhood: "kids have always played street hockey on the street, bike riding on the street, as well as playing with chalk. The parents are ALWAYS outside with their kids as most of them are small children just starting preschool" [National Post]. In their celebration of constant supervision of children's outdoor play, commenters produce an idealized childhood that not all people can equally attain, and which burdens some people more than others. Implicitly, these celebratory comments raise questions about the classed, and gendered implications of the practices they normalize.

Although intensive parenting discourses have long been understood as deeply gendered and burdensome on women (Hays, 1998), the ideals of children's outdoor play not only align with the gendered expectations of intensive mothering but expand them beyond the home, as now mothers must be vigilant in the streets, supervising their children and furthering their physical capital development (Stirrup, Duncombe, \& Sandford, 2014). The practices of the attentive and ever-present mother are influenced by moral judgements of parenting practices. Thomas, Stanford, \& Sarnecka (2016) found that estimates of risk associated with children being outside without parental supervision were biased by observers' (i.e. neighbours') moral disapproval of parents who left their children unsupervised. Similarly, Smyth \& Craig (2017) noted that one of the reasons that parents chose not to allow their children to play unsupervised outside were due to fears "associated with contravening normative expectations of good parenting" (p. 120).

The achievement of this idealized and monitored childhood is certainly easier when one possess the middle class circumstances and resources of time and money (Romagnoli \& Wall, 2012). For example, a consideration of how readers made sense of "Momma Bear" - the self- 
assigned name of a parent interviewed by reporters who was opposed to the ban - shows how discourses of risk are "strongly inflected with normative, middle-class values" (Howard, Dryden \& Johnson, 1999, p. 317). One reader dismisses Momma Bear's position by calling attention to the condition of her property, claiming that she wouldn't need to use the street as a play area "if she didn't have trash on her lawn" [CBC]. The pejorative reference to 'trash' positioned Momma Bear as culturally and economically inferior to the normative middle class, and thus outside the realm of respectability. It also positioned Momma Bear outside the realm of credibility since respectability connotes a form of moral authority - a means through which groups and individuals distinguish themselves from 'other' social and symbolic positions (Skeggs, 1997). Yet in a later comment, another reader comes to Momma Bear's defense: "Slow down right there. Momma Bear said her child has parental supervision while playing outside. I have known her family for 38 years. They are a well-respected family that looks after their children" $[\mathrm{CBC}]$. In this instance, the reader re-establishes Momma Bear's respectability by emphasizing her parental supervision of children playing outside.

The online commentary also offers insight regarding how readers assigned responsibility for ensuring that children had access to enriching outdoor play environments. When some readers took a closer look at the neighbourhood, they recognized the dearth of the play spaces for children, such as parks and playgrounds. One reader details the results of his search for information about the strata in an online comment:

Children need to play, any good parent will recognize that, however, i see in one pic no sidewalk, so i assume its an area where there is a sidewalk only on one side of the street, this is done to optimise space, and basically cram as many houses as they can in a given area, sorry, no place to raise children and no place to live in my opinion, come on, a child needs a yard, not a street to play on, if you have children, or are going to have 
children then you consider their needs now and in the future when buying or moving into an area, if you do not, then DO NOT have kids. [National Post]

Although the reader recognizes the structural and fiscal reasons why outdoor play space for children is minimized in this neighbourhood, ultimately the parent is identified as the entity to blame for children's lack of outdoor play. For example, the reader quoted above constructs the 'problem' as the consequence of a parent's choice - the choice to move into a neighbourhood that was, in their opinion, "no place to raise children" [CBC]. Further, the reader establishes some conditions regarding the deservingness of people to become parents that are based on a person's economic resources (i.e., having choices about where to live). In a just society, discussions of parental deservingness and laziness that manifest if a parent cannot prove their attentiveness and skilful risk management are extremely problematic (Smeyers, 2010) as intensive parenting is really only accessible to parents (mothers) who have the time and inclination to invoke it (i.e., the middle class).

\section{Discourses of nostalgia and the idealized imaginary of children's outdoor play}

Commenters also shared nostalgic depictions of their own childhoods, when the streets were a safe play space. Through invoking the language of what used to be, implicit is that childhood used to be better, and childhood today does not, and cannot, live up to yesteryear:

"When I was a kid, l'd be out of the house after breakfast exploring the neighbourhood-riding bikes, playing street hockey, being harmlessly mischievous...It's part of being a kid" [National Post]. Through the telling and retelling of a romanticized and widely shared version of the free roaming child, nostalgia functioned within these data as a means of opposing changes that would ban children's play in the streets, by pointing to the practices of a past time as a source of pride. 
In these nostalgic stories, commenters describe themselves as independent or in the company of other children and thus parents were completely absent. Children in these stories seemed to have a sense of adventure and danger but also implicitly understood what was safe and what was not. When adult supervision of children's play was mentioned, it was assigned to the community more generally rather than to parents, thus idealizing the community-minded nature of people in the generalized past, which afforded children freedom to play without parental supervision: "there was a time when kids were tolerated in public places, and everybody watched out for them because they were too small to watch out for themselves" [CBC]. Jane Jacobs (1961) positioned streets as ideal play spaces because they are integrated into the life of a community, rather than relegating children to a child-segregated space. That is, she advocated for street play because children were inherently supervised by adults going about their everyday lives. Modern day nostalgia then, laments the degradation of communitymindedness that has resulted in the need for parents to carefully monitor their children's whereabouts.

In our data, nostalgia made the teller a moral expert - as someone who has experienced first-hand the idealized childhood (fun, free, and full of neighbourhood nature-based roaming) - and makes their stated opinion a finality, or not up for discussion: "Shame on the strata do they not remember being a kid and the joys of playing outside and riding with their friends?" [CBC]. Nostalgia functioned to make invisible and less real ("shame on you!") realities of a past that do not adhere to this narrative, such as children who did not have access to this type of play or parental encouragement to wander in forest environments. As noted by Watson and Wells (2005), nostalgia "operates with an idealized imaginary of the past" (p. 24), "producing a 
collective memory that reflects only some people's lives" (p. 20). As a result, nostalgic

discourses often gloss over inequities and social injustices, presenting the play of the past as accessible to all and therefore experienced by all children regardless of gender, race, or class. In the following quote, the writer recalls the nostalgic pleasures of childhood free play:

We sure knew how to have fun when we were kids...We hiked everywhere you could imagine for an average 3 hours. We made tree forts or dug holes in the bush and made forts. We played cowboys and...sorry about that, almost said it." [CBC]

By 'almost saying something' this commenter 'all the way' says something; the reader can easily fill in the blanks. The use of the language 'almost saying something' is a linguistic move that functions to make the commenter's politics known: a person who resists modern day political correctness (i.e., the request of a marginalized group not to be called something) and perceived social change. Through their statement ["sorry about that"] they reveal that they are not really sorry and also expose a truism of nostalgia; that it works to maintain White Supremacy, in this instance, by pointing to a specific racist childhood game that invokes the White cowboy as hero and Indigenous peoples as savages. The commenter's frustrations with their ostensive inability to 'fully say something' points to their displeasure about not being able to fully access their romanticised childhood memories and the impossibility of the play of the past taking place in the present or future.

Among the activities for which readers wax nostalgic is road hockey, a game long associated with the quintessential Canadian identity (Hughes-Fuller, 2003; Robidoux, 2002). Sucharov (2013) wrote that within nostalgia for the Canadian past, "popular cultural expressions may give voice to quiet longings that are repressed in the name of the liberal values of inclusion" (p. 557). In other words, comments expressing nostalgia for the times when a pick- 
up game of street hockey was an everyday occurrence may collectively mask loss and longing for the White, patriarchal, heteronormative society within which such activities occurred (Robidoux, 2002). In response to a commenter noting that roads should be used exclusively for driving, one commenter responds: "everywhere I lived had street hockey, kids playing hide and seek and parents having everyone over for BBQ's... this is Canada!" [National Post]. Here, the specific reference to a national pastime is a means of claiming (road) space for people perceived to have a rightful claim to a Canadian identity. The underlying message is that "real" Canadians know that playing in the streets is part of what it means to be Canadian, and that those who oppose it are both unwelcome and un-Canadian.

Nostalgia also serves to promote White Supremacy through an insidious singular narrative that all children roamed freely and safely throughout their rural and urban neighbourhoods. The reality, however, is that space is intentionally constructed and organized to keep white children safe and place marginalized children in more danger than other children, through practices of, for example, environmental racism (Bullard, 1993). Marginalized kids are more likely to live in neighbourhoods that are close to toxic industrial effluent (Kershaw, Gower, Rinner, \& Campbell, 2013) and families on low income lack access to parks that are close to home, large in size and that are safe (Rigolon, 2016). Due to a lack of safe spaces to play, Indigenous children are more exposed to unintentional injury, injuries that are associated with outdoor play, than other children (Möller, Falster, Ivers, \& Jorm, 2015; Alaghehbandan, Sikdar, MacDonald, Collins, \& Rossignol, 2010). In short, through invoking nostalgia, the idealized childhood (the ideal white middle class outdoor childhood) is made coherent and normal. 
What is also implicit in this nostalgic discourse is a fear about what the future will hold if children are not able to access this imaginary and often inaccessible childhood: "if there was ever a sound of democracy dying, of humanity slipping inexorably towards extinction, banning children from playing, this is it. For serious, SHAME ON YOU FREELANCE STRATA" [CBC]. Although perhaps tongue in cheek, the commenter reveals an anxiety about the state of the future should children not be allowed to 'be children' and learn: "playing and inventing and learning how to cope with the next 80 years" through "some risk so that children have room to grow" [CBC]. One commenter is less melodramatic in their worry about the future, but brings forth the same point as the commenter above: "why do people have to be so stuffy, they are our future, let them play, so long as they are safe" $[C B C]$. The clear anxiety around this child issue is what Edelman (2004) articulated as a "function of the child as a prop of the secular theology upon which our social reality rests" (p.12). In other words, this romanticized childhood is a central cultural story around which an imaginary, idyllic and futuristic 'Child' is created that should be strived for. As such, children as not whole in and of themselves but, an "about to be realized identity" (p.13).

Nostalgia positions playing outside as a natural part of childhood. It is what children do. It is what children are and will be. Who, then, can be against the 'Child?': "This could potentially be a human rights complaint. The residents should investigate whether the Strata bylaws are infringing on the charter rights of their children" $[C B C]$. Nostalgia, then, is not just about a sense of loss and recollecting the past, but an active fretting about an idealistic future.

\section{Conclusion}


As naturally occurring data, online news comments enable an examination of a public's sense-making of issues- in this case, children's outdoor play - and the discourses that are invoked in doing so (McDermott, 2018). Reader comments, both for and against the ban on street play, accessed discourses of risk that produced an idealized childhood based on close parental supervision; however, this type of parental supervision is gendered and classed. Parents (mothers) are placed in an impossible position navigating their children's time and play spaces. Both by onlookers and in online forums, they are judged for being too close to their kids and quashing the natural growth that the outdoors provides, as well as for exposing their kids to adverse amounts of risk should they be too absent.

As a method, Foucauldian discourse analysis aspires to dissect, disrupt, and render the familiar strange by interrogating the norm (Graham, 2005). For example, nostalgic discourse, the feeling that something (unfettered, wholesome outdoor play) has been lost and cannot be reclaimed, makes the absent parent ideal through the free and roaming child. But, nostalgia, in normalizing children's outdoor play space as White and middle-class, also makes claims about who the ideal childhood experience is for. While marginalized children continue to experience disadvantage that inherently exposes them to risks daily, White, middle class children already have access to safer streets, both parent presence or unquestioned appropriate parental absence, and play in the streets can be part of their everyday lives. Ultimately, our analysis shows how discourses of risk and nostalgia produce idealized childhoods that influence the materiality of childhood, including how a child's time is organized and who gets to organize it, how play is experienced and who gets to experience it; in ideal ways, in ideal spaces and for the ideal child. 


\section{References}

Alaghehbandan, R., Sikdar, K. C., MacDonald, D., Collins, K. D., \& Rossignol, A. M. (2010). Unintentional injuries among children and adolescents in Aboriginal and non-Aboriginal communities, Newfoundland and Labrador, Canada. International Journal of Circumpolar Health, 69(1), 61-71.

Alexander, S. A., Frohlich, K. L., \& Fusco, C. (2018). Play, physical activity and public health: The reframing of children's leisure lives. London: Routledge.

Allin, L., West, A., \& Curry, S. (2014). Mother and child constructions of risk in outdoor play. Leisure Studies, 33(6), 644-657.

Barnes, K., Waitt, G., Gill, N., \& Gibson, C. (2006). Community and nostalgia in urban revitalisation: a critique of urban village and creative class strategies as remedies for social 'problems'. Australian Geographer, 37(3), 335-354.

Beck, U. (1992). Risk society: Towards a new modernity. New Delhi: Sage.

Bullard, R. D. (Ed.). (1993). Confronting environmental racism: Voices from the grassroots. South End Press.

Caputo, V. (2007). She's from a 'good family': Performing childhood and motherhood in a Canadian private school setting. Childhood, 14(2), 173-192.

Cheek, J. (2008). Foucauldian discourse analysis. In L.M. Given (Ed.) The SAGE Encyclopedia of qualitative research methods (pp. 355-358). Thousand Oaks: Sage.

Derbyshire, D. (2007, June 15). How children lost the right to roam in four generations. Daily Mail. Retrieved from https://www.dailymail.co.uk

Edelman, L. (2004). No future: Queer theory and the death drive. Chapel Hill, NC: Duke University Press.

Elvin-Nowak, Y. 1999. Accompanied by Guilt: Modern Motherhood the Swedish Way. (Doctoral thesis, Stockholm University). Stockholm: Stockholm University.

Faircloth, C. (2014). Intensive parenting and the expansion of parenting. In E. Lee, J. Bristow, C. Faircloth, \& J. Macvarish (Eds), Parenting culture studies (pp. 25-50). New York: Palgrave Macmillan.

Fotel, T. (2009). Marginalized or empowered? Street reclaiming strategies and the situated politics of children's mobilities. Geography Compass, 3, 1267-1280.

Foucault, M. (1972). The archaeology of knowledge. London: Tavistock Publications. 
Foucault, M. (1990). The history of sexuality: An introduction, volume I. Trans. Robert Hurley. New York: Vintage.

Gaster, S. (1991). Urban children's access to their neighborhood: Changes over three generations. Environment and Behavior, 23(1), 70-85.

Giles, A.R., Bauer, M.E.E., \& Darroch, F.E. (2019) Risky statement? A critique of the Position Statement on Active Outdoor Play. World Leisure Journal, 61(1), 58-66.

Graham, L. J. (November 27, 2005). Discourse analysis and the critical use of Foucault. Paper presented at the at Australian Association for Research in Education Annual Conference. Sydney, Australia.

Hanna, P., Scarles, C., Cohen, S., \& Adams, M. (2016). Everyday climate discourses and sustainable tourism. Journal of Sustainable Tourism, 24(12), 16624-1640.

Hays, S. (1996). The cultural contradictions of motherhood. New Haven, CT: Yale University Press.

Hoffman, D.M. (2010) Risky investments: Parenting and the production of the 'resilient child'. Health, Risk \& Society, 12(4), 385-394.

Holloway, S. L., \& Pimlott-Wilson, H. (2014). Enriching children, institutionalizing childhood? Geographies of play, extracurricular activities, and parenting in England. Annals of the Association of American Geographers, 104(3), 613-627.

Howard, S., Dryden, J., \& Johnson, B. (1999). Childhood resilience: Review and critique of literature. Oxford Review of Education, 25(3), 307-323.

Hughes-Fuller, P. “Am I Canadian?" Hockey as "National” culture? (2003). In J. Gifford \& G. Zezulka-Mailloux (Eds.), Culture and the state: Nationalisms (pp. 40-52). Edmonton, AB: CRC Humanities Studio.

Hughey, M. W., \& Daniels, J. (2013). Racist comments at online news sites: A methodological dilemma for discourse analysis. Media, Culture, and Society, 35(3), 332-247.

Jackson, L., \& Valentine, G. (2014). Emotion and politics in a mediated public sphere: Questioning democracy, responsibility and ethics in a computer mediated world. Geoforum, 52, 193-202.

Jackson, S. and Scott, S. (1999) Risk anxiety and the social construction of childhood. In D. Lupton (Ed.) Risk and sociocultural theory: New directions and perspectives (pp. 86-107). Cambridge: Cambridge University Press. 
Jacobs, J. (1961). The death and life of great American cities. New York: Vintage.

Karsten, L. (2005). It all used to be better? Different generations on continuity and change in urban children's daily use of space. Children's Geographies, 3(3), 275-290.

Kehily, M. J. (2010). Childhood in crisis? Tracing the contours of 'crisis' and its impact upon contemporary parenting practices. Media, Culture, and Society, 32(2), 171-185.

Kenny, M. (2017). Back to the populist future? Understanding nostalgia in contemporary ideological discourse. Journal of Political Ideologies, 22(3), 256-273.

Kershaw, S., Gower, S., Rinner, C., \& Campbell, M. (2013). Identifying inequitable exposure to toxic air pollution in racialized and low-income neighbourhoods to support pollution prevention. Geospatial Health, 7(2), 265-278.

Lester, S., \& Russell, W. (2014). Turning the world upside down: Playing as the deliberate creation of uncertainty. Children, 1(2), 241-260.

Louv, R. (2008). Last child in the woods: Saving our children from nature-deficit disorder. Chapel Hill, NC: Algonquin books.

Markula, P., \& Silk, M. (2011). Qualitative research for physical culture. New York: Palgrave Macmillan.

McLaren, A. T., \& Parusel, S. (2015). 'Watching like a hawk': Gendered parenting in automobilized urban spaces. Gender, Place, \& Culture, 22(10), 1426-1444.

McDermott, L. (2018). Online news comments as a public sphere forum: Deliberations on Canadian children's physical activity habits. International Review for the Sociology of Sport, 53(2), 173-196.

Möller, H., Falster, K., Ivers, R., \& Jorm, L. (2015). Inequalities in unintentional injuries between indigenous and non-indigenous children: A systematic review. Injury Prevention, 21(e1), e144-e152.

O'Brien, M., Jones, D., Sloan, D., \& Rustin, M. (2000). Children's independent spatial mobility in the urban public realm. Childhood, 7(3), 257-277.

O'Connor, J. (2018, July 8). No hockey, bikes, chalk drawings, you name it: This B.C. neighbourhood has declared a war on fun. Calgary Herald. Retrieved from http://www.calgaryherald.com/news/

Osler, J. (2016, March 30). Playgrounds begin to focus on riskier play. CBC Online News. Retrieved from https://www.cbc.ca/news/ 
Outdoor Play and Learning Coalition (2018). Scotland's Outdoor Play and Learning Coalition Position Statement. Retrieved from https://www.playscotland.org/playful-learning/

Pain, R. (2006). Paranoid parenting? Rematerializing risk and fear for children. Social \& Cultural Geography, 7(2), 221-243.

Rigolon, A. (2016). A complex landscape of inequity in access to urban parks: A literature review. Landscape and Urban Planning, 153, 160-169.

Rixon, A., Lomax, H., \& O’Dell, L. (2019): Childhoods past and present: Anxiety and idyll in reminiscences of childhood outdoor play and contemporary parenting practices, Children's Geographies. Advance online publication. DOI:

10.1080/14733285.2019.1605047

Robidoux, M. A. (2002). Imagining a Canadian identity through sport: A historical interpretation of lacrosse and hockey. Journal of American Folklore, 115, 209-225.

Romagnoli, A., \& Wall, G. (2012). 'I know I'm a good mom': Young, low-income mothers' experiences with risk perception, intensive parenting ideology and parenting education programmes. Health, Risk \& Society, 14(3), 273-289.

Sandseter, E. B. H. (2014). Early years outdoor play in Scandinavia. In T. Maynard \& J. Waters (Eds), Exploring outdoor play in the early years (pp. 114-126). Maidenhead, UK: Open University Press.

Skeggs, B. (1997). Formations of Class \& Gender: Becoming Respectable. Thousand Oaks: Sage.

Skenazy, L. (2010). Free-range kids: How to raise safe, self-reliant children (without going nuts with worry). San Francisco: Jossey-Bass.

Smeyers, P. (2010). Child rearing in the "Risk" Society: on the Discourse of Rights and the "Best Interests of a Child". Educational Theory, 60(3), 271-284.

Smyth, C., \& Craig, L. (2017). Conforming to intensive parenting ideals: willingness, reluctance and social context. Families, Relationships and Societies, 6(1), 107-124.

Stirrup, J., Duncombe, R., \& Sandford, R. (2014). 'Intensive mothering' in the early years: The cultivation and consolidation of (physical) capital. Sport, Education, and Society, 20(1), 89106.

Sucharov, M. (2013). Imagining ourselves then and now: Nostalgia and Canadian multiculturalism. Journal of International Relations and Development, 26, 539-565.

Szto, C. (2016). \# LOL at Multiculturalism: Reactions to Hockey Night in Canada Punjabi From 
the Twitterverse. Sociology of Sport Journal, 33(3), 208-218.

Tremblay, M., Gray, C., Babcock, S., Barnes, J., Bradstreet, C., Carr, D, Chabot, C., Choquette, L., Chorney, D., Collyer, C., Herrrington, S., Janson, K., Janssen, I., Larouche, R., Pickett, W., Power, M., Sandseter, E.B.H., Simon, B., \& Brussoni, M. (2015). Position statement on active outdoor play. International Journal of Environmental Research and Public Health, 12(6), 6475-6505.

Thomas, A. J., Stanford, P. K., \& Sarnecka, B. W. (2016). No child left alone: Moral judgments about parents affect estimates of risk to children. Collabra, 2(1), 1-14.

Vandermaas-Peeler, M., Dean, C., Biehl, S. M. \& Mellman, A. (2019). Parents' beliefs about young children's play and nature experiences in Danish and US contexts. Journal of Adventure Education and Outdoor Learning, 19(1), 43-55.

United Nations Children's Fund UK. 1989). The United Nations convention on the rights of the child. Retrieved from https://downloads.unicef.org.uk/

Valentine, G. (2017). Public space and the culture of childhood. London: Routledge.

Watson, S., \& Wells, K. (2005). Spaces of nostalgia: The hollowing out of a London market. Social and Cultural Geography, 6(1), 17-30.

Widding, U. (2015). Parenting ideals and (un-) troubled parent positions. Pedagogy, Culture \& Society, 23(1), 45-64.

Yogman, M., Garner, A., Hutchinson, J., Hirsh-Pasek, K., Golinkoff, R. M., \& Committee on Psychosocial Aspects of Child and Family Health. (2018). The power of play: A pediatric role in enhancing development in young children. Pediatrics, 142(3), e20182058.

Retrieved from https://pediatrics.aappublications.org/ 